Gut, 1972, 13, 107-111

\title{
Intraluminal fat digestion in the chronic alcoholic
}

\author{
GARY M. ROGGIN, FRANK L. IBER, AND WILLEM G. LINSCHEER ${ }^{2}$
}

From the Gastrointestinal Research Unit, Lemuel Shattuck Hospital, Department of Public Health, Commonwealth of Massachusetts, and from the Department of Medicine, Tufts University School of Medicine, Boston, Mass, USA

SUMMARY Intraluminal fat digestion and absorption were evaluated in 15 chronic alcoholic and nine healthy volunteer males by aspiration of a standard meal from the jejunum. Intraluminal bile salts were present in normal concentrations and micellar solubilization of fatty acids and monoglycerides was within normal limits. Pancreatic lipase concentrations, however, were significantly lower in the alcoholic patients. As a consequence, hydrolysis of triglycerides was slower resulting in abnormally low concentrations of fatty acids and micellar lipids. Recovery of lipase production toward normal was demonstrated after four to six weeks by repeated intubation studies. Thus, in the chronic alcoholic insufficient production of pancreatic lipase seems to be responsible for the reversible abnormality in the intraluminal digestion of fat.

Previous studies have demonstrated abnormalities of the extraluminal phase of absorption in noncirrhotic chronic alcoholic patients as evidenced by methionine (Israel, Valenzuela, Salazar, and Ugarte, 1969), d-xylose, and vitamin $B_{12}$ (Roggin, Iber, Kater, and Tobon, 1969) absorption studies. Increased faecal fat excretion was also observed in these patients. As excessive alcohol intake affects multiple organic functions; luminal as well as extraluminal factors may have been responsible for the observed fat malabsorption. The present investigation was undertaken to evaluate the intraluminal phase of fat absorption in chronic alcoholic inpatients and normal controls.

\section{Materials and Methods}

Intraluminal digestion of fat in the upper small bowel was studied in two groups of subjects. The first group consisted of 15 chronic alcoholic patients in hospital. They consumed more than $250 \mathrm{~g}$ of alcohol daily until admission. All had hepatomegaly (ie, $<15 \mathrm{~cm}$ in the anterior axillary line), but no patient had ascites, jaundice, endocrinopathy, or clinical evidence of nutritional deficiency. Routine liver

\footnotetext{
${ }^{1}$ The work reported upon in this paper was supported by contract no. DA-49-193-MD-2248 between Tufts University and the Office of The Surgeon General, Department of the Army, Washington, D.C.; NIH research grant no. AM-11566; and training grant no. AM-05424, US Public Health Service.

${ }^{2}$ Correspondence: Dr Willem G. Linscheer, Lemuel Shattuck Hospital, 170 Morton Street, Boston, Massachusetts 02130.
}

Received for publication 18 November 1971. function tests were normal except for minimal elevations of SGOT, ie, <100 Karmen units, in seven patients and alkaline phosphatase, ie, <3.5 BLU, in four. When the patients were discharged all these values had returned to normal. Bromsulphalein (BSP) determinations performed on all patients were also normal (less than $5 \%$ in $45 \mathrm{~min}$ ). All patients were studied within one week after admission to hospital and were abstinent for the entire period of study. The control group consisted of nine healthy volunteers who consumed less than $10 \mathrm{~g}$ of alcohol per week.

All patients underwent radiological evaluation of the upper gastrointestinal tract and had a biopsy of the jejunal mucosa. Faecal fat excretion was measured by fat balance studies performed on a metabolic ward (100 $\mathrm{g}$ fat diet for five days). Faecal fat was determined by the method of van de Kamer, ten Bokkel, Huinink, and Weyers (1949) utilizing a 72-hour stool collection. Employing the method of Roe and Rice (1948) d-xylose was determined for all subjects in a five-hour urine collection after oral administration of $25 \mathrm{~g}$ of d-xylose in $250 \mathrm{ml}$ of water.

\section{Intubation Studies}

The proximal jejunum of each subject was intubated after an overnight fast by passing a single lumen tube via the nasopharynx into the stomach, allowing it to reach a point $20 \mathrm{~cm}$ beyond the ligament of Treitz. The tube's position was checked fluoroscopically at the beginning and the end of each study. Patients and controls were fed a $300 \mathrm{ml}$ test meal consisting 
of $74 \mathrm{~g}$ of corn oil, $126 \mathrm{~g}$ of skimmed milk powder, and $138 \mathrm{~g}$ of dextrose homogenized in water to a volume of $1,000 \mathrm{ml}$. The intestinal contents were collected by gravity drainage during two 45 -minute periods is two aliquots, and immediately frozen in a dry ice-acetone bath and stored at $-20^{\circ} \mathrm{C}$ until analysis. One of the two frozen aliquots from each collection period was quickly thawed, then heated to $70^{\circ} \mathrm{C}$ for 10 minutes to inactivate pancreatic lipase before chemical analyses were performed.

Lipid was extracted from the intestinal contents by the following method (Krone, Theodor, Sleisenger, and Jeffries 1968): to $2 \mathrm{ml}$ of intestinal content, 0.5 $\mathrm{ml}$ of $0.5 \mathrm{M}$ solution of monosodium phosphate and $3.3 \mathrm{ml}$ of absolute methanol were added in a separatory funnel. The mixture was extracted three times with an equal volume of hexane $(5.8 \mathrm{ml})$. The three aliquots of hexane were pooled for subsequent lipid assays. The lower methanol-water phase was saved for bile salt analysis.

To separate micellar from emulsion lipid, $6 \mathrm{ml}$ of gauze-filtered intestinal content was centrifuged in a Beckman L-2 ultracentrifuge at $10^{5} \mathrm{~g}\left(30^{\circ} \mathrm{C}\right)$ for three hours. An aliquot of the clear infranatant solution of micellar lipid was collected by needle aspiration through the wall of the plastic centrifuge tube; its lipid content was extracted as described above.

Using a modification of Amenta's method (1964), the total lipid content of the intestinal samples and their micellar phases was determined. The pooled hexane phase of the extracted lipid sample was evaporated by heat to dryness; the residue resuspended in $0.5 \mathrm{ml}$ hexane. A $5 \mathrm{ml}$ aliquot was added to $2 \mathrm{ml}$ of an acid dichromate solution $(2.5 \mathrm{~g}$ of $\mathrm{K}_{2} \mathrm{CR}_{2} \mathrm{O}_{7}$ dissolved in 1 litre $36 \mathrm{~N} \mathrm{H}_{2} \mathrm{SO}_{4}$ ) and placed in a water bath at $100^{\circ} \mathrm{C}$ for 45 minutes. The tubes were cooled and centrifuged for 15 minutes. A $0.5 \mathrm{ml}$ aliquot from each clear supernatant solution was added to $10 \mathrm{ml}$ of water and its optical density was read at $350 \mathrm{~m}$ in a Beckman DU spectrophotometer against a water blank. A $5 \mathrm{ml}$ aliquot of the resuspended hexane extract was applied to silica gel plates and separated by standard thin-layer chromatographic techniques (Amenta, 1964).

Fatty acid content for each sample was found using the titration method of Dole (1956). The $p H$ of the intestinal samples was determined by a glass electrode after 30 minutes' equilibration with $5 \%$ $\mathrm{CO}_{2}$. An aliquot of intestinal juice, not exposed to heat, was analysed for pancreatic lipase using Dirstine's method (Dirstine, Sobell, and Henry, 1968).

Bile salt concentration in each intestinal sample was enzymatically determined (Admirand and Small, 1968). Bile salts were further analysed by thin-layer chromatography utilizing the solvent systems of Hofmann (1962) and 10\% phosphomolybdic acid as a colour indicator.

Faecal fat excretion and d-xylose absorption were determined at the beginning of the study period in 12 of 15 alcoholic patients. The small intestinal intubation with administration of the test meal was repeated after four to six weeks in 13 of 15 alcoholic patients; the intestinal contents were analysed as previously described.

\section{Results}

\section{ABSORPTION STUDIES}

The results are summarized in Table I.

\section{D-xylose absorption}

Five of 12 patients tested at the beginning of the study period had less than $5 \mathrm{~g}$ in the five hours. A urine sample showed three to be borderline and two

\begin{tabular}{|c|c|c|c|c|c|}
\hline \multirow{2}{*}{ Name } & \multirow{2}{*}{$\begin{array}{l}\text { Age } \\
(y r)\end{array}$} & \multirow{2}{*}{$\begin{array}{l}B S P \\
(\%)\end{array}$} & \multicolumn{2}{|c|}{$D$-xylose $(g / 5 \mathrm{hr})$} & \multirow{2}{*}{$\begin{array}{l}\text { Faecal Fat } \\
(g / 24 h r)\end{array}$} \\
\hline & & & Initial & Final & \\
\hline WK & 36 & 3 & $6 \cdot 0$ & $6 \cdot 5$ & $2 \cdot 3$ \\
\hline \multicolumn{6}{|l|}{$\begin{array}{l}\text { RH } \\
\text { JB }\end{array}$} \\
\hline TS & 55 & 2 & $3 \cdot 0$ & $8 \cdot 2$ & $5 \cdot 0$ \\
\hline JS & 52 & 1 & $5 \cdot 7$ & & $5 \cdot 1$ \\
\hline JMcI & 47 & 4 & $4 \cdot 4$ & $9 \cdot 4$ & $5 \cdot 7$ \\
\hline \multicolumn{6}{|l|}{ JB } \\
\hline JMcG & 30 & 3 & 4.9 & $7 \cdot 3$ & 3.0 \\
\hline JP & 50 & 0 & 6.9 & $9 \cdot 2$ & $4 \cdot 6$ \\
\hline EM & 56 & 1 & $4 \cdot 4$ & $9 \cdot \overline{3}$ & 4.5 \\
\hline \multicolumn{6}{|l|}{$\begin{array}{l}\mathrm{EM} \\
\text { JB }\end{array}$} \\
\hline AW & 36 & 0 & $10 \cdot 0$ & $8 \cdot 2$ & $2 \cdot 8$ \\
\hline $\mathbf{L M}$ & 29 & 5 & $7 \cdot 0$ & $8 \cdot 7$ & $3 \cdot 5$ \\
\hline WC & 47 & 3 & 6.5 & 6.5 & 1.9 \\
\hline JM & 29 & 3 & $7 \cdot 8$ & 6.0 & 6.9 \\
\hline
\end{tabular}

Table I Findings on admission and screening absorption studies in 15 alcoholic subjects 
definitely abnormal. When the determination was repeated at the end of the study period all values were within the normal range.

Faecal fat excretion

All but one patient had normal faecal fat excretion.

Upper gastrointestinal series and small bowel biopsy The 15 chronic alcoholic patients all demonstrated normal upper gastrointestinal series and small bowel histology.

\section{INTRALUMINAL STUDIES}

\section{Total and micellar lipid}

There was no significant difference in total lipid of the pooled 90-minute aspirate between the alcoholic and the control group $(10.4 \mathrm{mg} / \mathrm{ml} \pm 3.6$ (SD) vs $9.1 \mathrm{mg} / \mathrm{ml} \pm(\mathrm{SD}), \mathrm{P}>0.2)$. However, the mean concentration of lipid incorporated into micelles was significantly lower in the alcoholic group when compared with the controls $(4.2 \mathrm{mg} / \mathrm{ml} \pm 2 \cdot 2$ (SD) vs $7.1 \mathrm{mg} / \mathrm{ml} \pm 2.9, \quad P<0.005$ ) (Fig. 1). The average percentage of lipid in the micellar phase was $41.5 \pm 14.6$ compared with $79.3 \pm 22.6$ in the control group $(\mathrm{P}<0.0005)$. Thirteen alcoholic patients were restudied after four to six weeks in hospital. The mean percentage micellar lipid increased to $54.0 \pm 21.6(P<0.2)$.

\section{Fatty acid}

In nine of 14 alcoholic patients, the percentage of fatty acid in the total lipid phase was less than $\mathbf{5 0 .}$ The mean percentage of fatty acid in the alcoholic group was $49 \cdot 7 \pm 15 \cdot 1$ compared with $73.7 \pm 18.7$ for the control group $(P<0.01)$.

\section{Pancreatic lipase}

The average pancreatic lipase concentration for the pooled 90-minute sample for the alcoholic group was $106 \pm 72.1 \mathrm{moles} / \mathrm{ml}$ compared with $214 \pm 73.9$ for the control group $(P<0.001)$ (Fig. 2). The repeat study in 13 alcoholics after four to six weeks demonstrated an increase to $365 \pm 219(\mathrm{P}<0.01)$ (Fig. 3).

\section{Bile salt}

The mean total and micellar bile salt concentration for the pooled 90-minute sample was $12 \cdot 2 \pm 4 \cdot 8$ and $10.6 \pm 4.7 \mathrm{mM}$ in the alcoholic group, $10 \cdot 1 \pm 4.0$, and $6.7 \pm 2.8$ in the control group. In both groups, all patients exhibited total and micellar bile salt concentrations above the critical micellar concentration, ie, 1-2 mM. Thin-layer chromatography

\begin{tabular}{|c|c|c|c|c|c|c|c|c|c|c|}
\hline Name & $\begin{array}{l}\text { Total } \\
\text { Lipid } \\
(\mathrm{mg} / \mathrm{ml})\end{array}$ & $\begin{array}{l}\text { Micellar } \\
\text { Lipid } \\
(m g / m l)\end{array}$ & $\begin{array}{l}\text { Micellar } \\
\text { Lipid } \\
(\%)\end{array}$ & $\begin{array}{l}\text { Fatty } \\
\text { Acid } \\
(\%)\end{array}$ & $\begin{array}{l}\text { Total } \\
\text { Bile Salt } \\
(m M)\end{array}$ & $\begin{array}{l}\text { Micellar } \\
\text { Bile Salt } \\
(m M)\end{array}$ & $p H$ & $\begin{array}{l}\text { Pancreatic } \\
\text { Lipase } \\
(\mu M / m l)\end{array}$ & $\begin{array}{l}\text { Repeat } \\
\text { Micellar } \\
\text { Lipid } \\
(\%)\end{array}$ & $\begin{array}{l}\text { Repeat } \\
\text { Pancreatic } \\
\text { Lipase } \\
(\mu M / m l)\end{array}$ \\
\hline $\begin{array}{l}\text { WK } \\
\text { RH } \\
\text { JB } \\
\text { TS } \\
\text { JS } \\
\text { JMcI } \\
\text { JB } \\
\text { JMcG } \\
\text { JP } \\
\text { EM } \\
\text { JB } \\
\text { AW } \\
\text { LM } \\
\text { WC } \\
\text { JM }\end{array}$ & $\begin{array}{c}8 \cdot 45 \\
11 \cdot 85 \\
14 \cdot 8 \\
12 \cdot 7 \\
16 \cdot 5 \\
10 \cdot 78 \\
10 \cdot 0 \\
10 \cdot 8 \\
8 \cdot 4 \\
7 \cdot 18 \\
3 \cdot 7 \\
13 \cdot 23 \\
4 \cdot 0 \\
11 \cdot 2 \\
12 \cdot 72\end{array}$ & $\begin{array}{l}2 \cdot 08 \\
5 \cdot 0 \\
4 \cdot 5 \\
0 \cdot 58 \\
9 \cdot 18 \\
3 \cdot 7 \\
5 \cdot 0 \\
3 \cdot 58 \\
5 \cdot 6 \\
3 \cdot 8 \\
1 \cdot 6 \\
6 \cdot 6 \\
1 \cdot 9 \\
5 \cdot 0 \\
5 \cdot 53\end{array}$ & $\begin{array}{r}24 \cdot 6 \\
42 \cdot 2 \\
30 \cdot 4 \\
4 \cdot 6 \\
55 \cdot 8 \\
34 \cdot 3 \\
50 \cdot 0 \\
33 \cdot 3 \\
66 \cdot 7 \\
52 \cdot 8 \\
43 \cdot 2 \\
49 \cdot 6 \\
47 \cdot 5 \\
44 \cdot 6 \\
43 \cdot 3\end{array}$ & $\begin{array}{l}74 \cdot 6 \\
38 \cdot 1 \\
42 \cdot 6 \\
44 \cdot 9 \\
39 \cdot 4 \\
43 \cdot 6 \\
34 \cdot 0 \\
70 \cdot 0 \\
72 \cdot 3 \\
64 \cdot 0 \\
\overline{48} \cdot 0 \\
40 \cdot 0 \\
27 \cdot 6 \\
56 \cdot 6\end{array}$ & $\begin{array}{r}8 \cdot 7 \\
14 \cdot 5 \\
7 \cdot 1 \\
4 \cdot 8 \\
16 \cdot 9 \\
13 \cdot 6 \\
16 \cdot 6 \\
22 \cdot 8 \\
12 \cdot 1 \\
11 \cdot 8 \\
12 \cdot 6 \\
9 \cdot 4 \\
6 \cdot 2 \\
15 \cdot 8 \\
14 \cdot 4\end{array}$ & $\begin{array}{r}8 \cdot 0 \\
11 \cdot 8 \\
5 \cdot 8 \\
4 \cdot 6 \\
16 \cdot 5 \\
12 \cdot 3 \\
16 \cdot 3 \\
16 \cdot 0 \\
13 \cdot 3 \\
10 \cdot 8 \\
12 \cdot 0 \\
5 \cdot 2 \\
2 \cdot 2 \\
\overline{13} \cdot 6\end{array}$ & $\begin{array}{l}6 \cdot 26 \\
7 \cdot 16 \\
6 \cdot 35 \\
6 \cdot 17 \\
6 \cdot 5 \\
6 \cdot 4 \\
6 \cdot 52 \\
6 \cdot 71 \\
6 \cdot 3 \\
6 \cdot 8 \\
6 \cdot 4 \\
5 \cdot 9 \\
5 \cdot 9 \\
6 \cdot 5 \\
5 \cdot 9\end{array}$ & $\begin{array}{r}92 \cdot 0 \\
173 \cdot 0 \\
283 \cdot 0 \\
174 \cdot 0 \\
151 \cdot 3 \\
65 \cdot 4 \\
52 \cdot 4 \\
101.1 \\
173 \cdot 1 \\
60 \cdot 2 \\
72.9 \\
80.0 \\
22.5 \\
7.5 \\
81.7\end{array}$ & $\begin{array}{l}\overline{33.0} \\
56 \cdot 0 \\
- \\
66 \cdot 3 \\
88 \cdot 0 \\
\overline{48.0} \\
20 \cdot 0 \\
85 \cdot 0 \\
66 \cdot 0 \\
66 \cdot 0 \\
\overline{27} \cdot 0 \\
39.0\end{array}$ & $\begin{array}{r}\overline{740 \cdot 0} \\
520 \cdot 0 \\
483 \cdot 0 \\
385 \cdot 0 \\
38 \cdot 6 \\
142 \cdot 0 \\
436 \cdot 0 \\
420 \cdot 0 \\
356 \cdot 0 \\
135 \cdot 0 \\
145 \cdot 0 \\
\overline{193} \cdot 0 \\
754 \cdot 0\end{array}$ \\
\hline $\begin{array}{l}\text { Mean } \\
\text { SD }\end{array}$ & $\begin{array}{r}10.42 \\
3.61\end{array}$ & $\begin{array}{l}4 \cdot 24 \\
2 \cdot 18\end{array}$ & $\begin{array}{l}41 \cdot 5 \\
14 \cdot 3\end{array}$ & $\begin{array}{l}49 \cdot 71 \\
15 \cdot 14\end{array}$ & $\begin{array}{r}12 \cdot 19 \\
4 \cdot 78\end{array}$ & $\begin{array}{r}10 \cdot 58 \\
4 \cdot 67\end{array}$ & $\begin{array}{l}6 \cdot 38 \\
0 \cdot 348\end{array}$ & $\begin{array}{r}106 \cdot 01 \\
72 \cdot 15\end{array}$ & $\begin{array}{l}54 \cdot 0 \\
21 \cdot 6\end{array}$ & $\begin{array}{l}365 \cdot 1 \\
219 \cdot 4\end{array}$ \\
\hline $\begin{array}{c}\text { JC } \\
\mathbf{G} \\
\mathbf{J G} \\
\mathbf{H} \\
\mathbf{J H} \\
\mathbf{J M} \\
\mathbf{M} \mathbf{c} \\
\mathbf{M} \\
\mathbf{B}\end{array}$ & $\begin{array}{c}10 \cdot 4 \\
8 \cdot 2 \\
6 \cdot 6 \\
9 \cdot 75 \\
6 \cdot 03 \\
5 \cdot 8 \\
16 \cdot 6 \\
- \\
-\end{array}$ & $\begin{array}{c}10 \cdot 0 \\
8 \cdot 0 \\
3 \cdot 3 \\
10 \cdot 9 \\
4 \cdot 0 \\
5 \cdot 35 \\
8 \cdot 0 \\
- \\
-\end{array}$ & $\begin{array}{r}96 \cdot 2 \\
97 \cdot 6 \\
50 \cdot 0 \\
100 \cdot 0 \\
66 \cdot 7 \\
93 \cdot 1 \\
48 \cdot 2 \\
-\end{array}$ & $\begin{array}{l}79 \cdot 1 \\
92 \cdot 1 \\
64 \cdot 5 \\
90 \cdot 3 \\
63 \cdot 7 \\
86 \cdot 2 \\
40 \cdot 2 \\
- \\
-\end{array}$ & $\begin{array}{r}11 \cdot 6 \\
12 \cdot 8 \\
14 \cdot 7 \\
5 \cdot 1 \\
4 \cdot 5 \\
13 \cdot 7 \\
6 \cdot 7 \\
13.7 \\
7 \cdot 9\end{array}$ & $\begin{array}{c}4 \cdot 8 \\
10 \cdot 7 \\
9 \cdot 2 \\
5 \cdot 0 \\
3 \cdot 9 \\
3 \cdot 57 \\
6 \cdot 0 \\
10 \cdot 7 \\
6 \cdot 3\end{array}$ & $\begin{array}{l}5 \cdot 8 \\
6 \cdot 0 \\
6 \cdot 5 \\
6 \cdot 4 \\
6 \cdot 2 \\
6 \cdot 0 \\
6 \cdot 3 \\
6 \cdot 4 \\
6 \cdot 2\end{array}$ & $\begin{array}{r}232.5 \\
161 \cdot 4 \\
223 \cdot 5 \\
93 \cdot 0 \\
199.0 \\
189.0 \\
300.0 \\
185.0 \\
343.0\end{array}$ & $\begin{array}{l}- \\
- \\
z \\
z \\
- \\
-\end{array}$ & $\begin{array}{l}- \\
- \\
- \\
- \\
- \\
-\end{array}$ \\
\hline $\begin{array}{l}\text { Mean } \\
\text { SD }\end{array}$ & $\begin{array}{r}9.05 \\
3.78\end{array}$ & $\begin{array}{l}7.08 \\
2.93\end{array}$ & $\begin{array}{l}78 \cdot 8 \\
21 \cdot 4\end{array}$ & $\begin{array}{l}73 \cdot 73 \\
18 \cdot 74\end{array}$ & $\begin{array}{r}10.08 \\
4.02\end{array}$ & $\begin{array}{l}6 \cdot 69 \\
2 \cdot 8\end{array}$ & $\begin{array}{l}6 \cdot 2 \\
0 \cdot 229\end{array}$ & $\begin{array}{r}214 \cdot 18 \\
73 \cdot 85\end{array}$ & - & - \\
\hline$P$ value & 0.2 & 0.005 & 0.005 & 0.01 & 0.15 & 0.01 & $0 \cdot 1$ & 0.001 & - & - \\
\hline
\end{tabular}

Table II Intraluminal studies in 15 alcoholic and nine normal subjects 


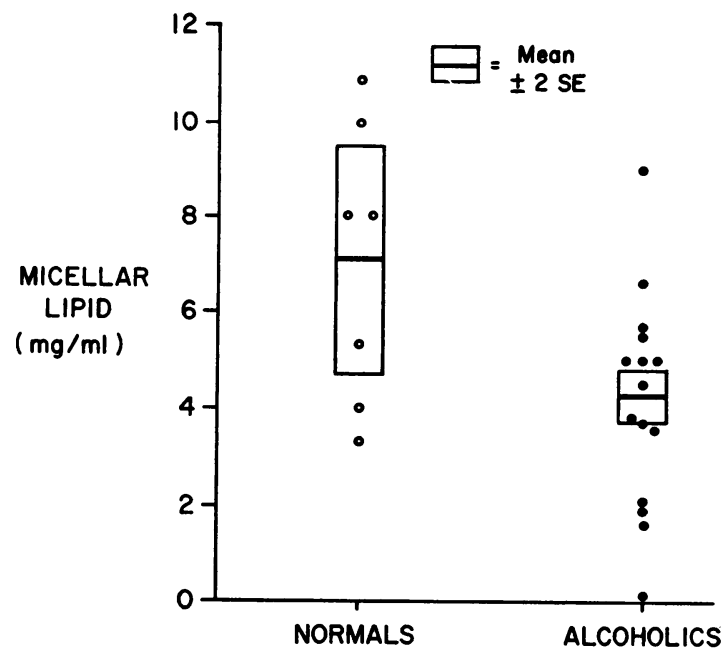

Fig. 1 Micellar lipid in bowel juice $(\mathrm{mg} / \mathrm{ml})$

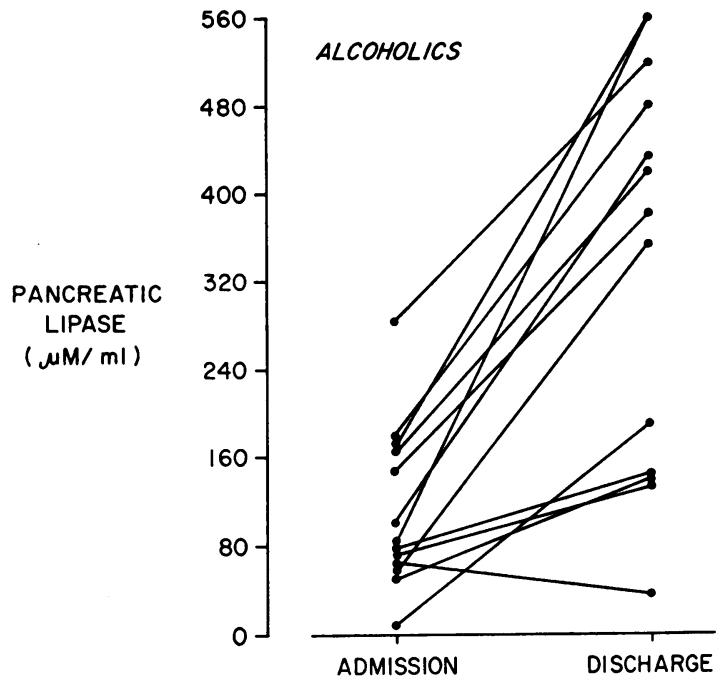

Fig. 3 Follow-up studies of pancreatic lipase in bowel juice of the alcoholic subjects (4-6 weeks later) $(\mu \mathrm{M} / \mathrm{ml})$

revealed negligible quantities of unconjugated bile salts in two subjects.

$p H$

The mean intraluminal $p \mathrm{H}$ for the pooled 90-minute sample in the alcoholic group was $6.4 \pm 0.35$ (SD) and $6.2 \pm 0.23$ in the control group (P>0.1).

\section{Discussion}

Abnormal intestinal functions have frequently been

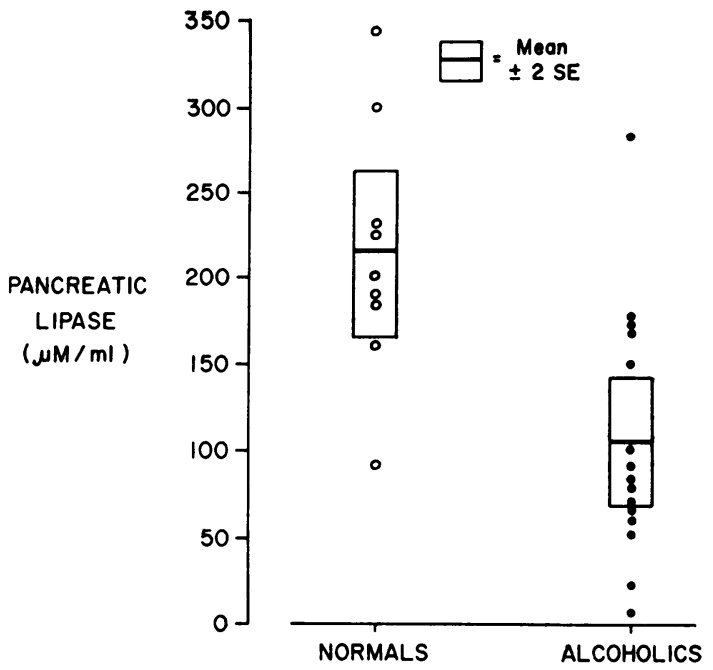

Fig. 2 Pancreatic lipase in bowel juice $(\mu M / m l)$

reported in chronic alcoholic patients. Since alcoholic patients are often admitted for liver decompensation, it is not surprising that most of these studies involved alcoholics with cirrhosis. It is well established that fat malabsorption is present in 40 to $50 \%$ of patients admitted to hospital with cirrhosis (Baraona, Orrego, Fernández, Amenabar, Maldonado, Tag, and Salinas, 1962; Van Goidsenhoven, Henke, Vacca, and Knight, 1963; Linscheer, Patterson, Moore, Clermont, Robins, and Chalmers, 1966).

Recent studies of alcoholic cirrhotics have demonstrated abnormally low concentrations of bile salts in bowel juice during the absorption of a test meal (Linscheer, Roggin, and Patterson, 1970), but lipase concentrations have not been different from normal controls. Vlahcevic, Buhac, Farrar, Cooper Bell, Jr, and Swell (1971) showed the bile salt pool to be decreased in patients with alcoholic cirrhosis.

The effect of the cirrhotic liver on the intraluminal phase of absorption has been clearly demonstrated by Badley, Murphy, Bouchier, and Sherlock (1970) by studying patients with non-alcoholic cirrhosis and steatorrhoea. Such patients presented normal lipase concentrations and impaired micellar solubilization was thought to be due to bile salt deficiency. These observations are similar to our findings in alcoholic cirrhotic patients.

We studied previously non-cirrhotic chronic alcoholic males and found abnormalities in the absorption of d-xylose ( $76 \%$ of the patients) and vitamin $B_{12}$ $(47 \%)$ and the excretion of faecal fat $(60 \%)$ and nitrogen (52\%) (Roggin et al, 1969). A combination of mucosal defects and altered intraluminal digestion, ie, $p \mathrm{H}$, bile salts, and pancreatic secretion, was 
thought to be responsible in the pathogenesis of the steatorrhoea observed in these patients. The present study is a direct evaluation of intraluminal fat digestion in a group of chronic non-cirrhotic alcoholic males when they had stopped drinking with a reevaluation of the same patients after a period of abstinence of four to six weeks.

The intraluminal $p \mathrm{H}$ or bile salt concentrations did not change in the alcoholics. They were not signifcantly different from the controls. Thin-layer chromatography did not reveal any appreciable quantities of unconjugated bile salts in either group. Both micellar and total fatty acid concentrations were, however, decreased in bowel juice of the alcoholics. These observations point to a slower rate of hydrolysis of the triglycerides, corresponding with the lipase deficiency as demonstrated in the alcoholics. When intraluminal studies were repeated in the alcoholic group after a period of abstinence of four to six weeks most patients demonstrated improvement in both pancreatic lipase and micellar lipid incorporation. It thus appears that chronic alcoholic patients have a reversible abnormality in intraluminal digestion which may be due to a deficiency in pancreatic lipase.

The association of chronic alcoholism and pancreatic dysfunction is well recognized. A recent study by Mezey, Jow, Slavin, and Tobon (1970) demonstrated the frequent occurrence, in chronic alcoholic patients, of diminished pancreatic outflow following secretin stimulation. In these studies pancreatic function was evaluated by measuring pancreatic bicarbonate and enzyme production after maximal stimulation. Unfortunately, it is difficult to correlate maximal pancreatic output with the capacity of the pancreas to produce enough bicarbonate and enzymes for normal digestion. Our study was designed to evaluate the intraluminal phase of fat absorption in alcoholic patients during the digestion of a standard test meal. We found that despite delayed hydrolysis of intraluminal triglycerides, faecal fat excretion was normal in most patients. This indicated that, at least for practical purposes, fat absorption was completed more distally in the small intestine.

The cause of pancreatic insufficiency may be related to protein deficiency. A high incidence of abnormal pancreatic functions has been diagnosed in protein-deficient populations (Shaper, 1964) and is readily reversible upon protein refeeding (Tandon, Banks, and George, 1970). The protein intake of our patients was usually low before admission. In our patients, as was true in those of Mezey, pancreatic function returned towards normal within six weeks of sobriety and an adequate protein intake.

A number of the alcoholic patients had a mild disturbance of liver function (SGOT $<100 \mathrm{KU}$, alkaline phosphatase $<$ BLU) which disappeared at the end of the study. Intestinal bile salt concentrations, however, were not different from those of controls and did not change.

Thus, in the absence of cirrhosis abnormal luminal digestion in the chronic alcoholics was a reversible condition probably related to lipase deficiency.

We are grateful to Patricia Burns, Hans Dekker, and Sheila Liberman for the laboratory determinations and to Mrs Theresa Bulman and the nursing staff, Clinical Research Unit.

\section{References}

Admirand, W. H., and Small, D. M. (1968). The physicochemical basis of cholesterol gallstone formation in man. J. clin Invest., 47, 1043-1052.

Amenta, J. S. (1964). A rapid chemical method for quantification of lipids separated by thin-layer chromatography. J. Lipid Res., 5, 270-272.

Badley, B. W. D., Murphy, G. M., Bouchier, I. A. D., and Sherlock, S. (1970). Diminished micellar phase lipid. Gastroenterology, 58, 781-789.

Baraona, E., Orrego, H., Fernández, O., Amenabar, E., Maldonado, E., Tag, F., and Salinas, A. (1962). Adsorptive function of the small intestine in liver cirrhosis. Amer. J. dig. Dis., 7, 318-330.

Dirstine, P. H., Sobel, C., and Henry, R. J. (1968). A new rapid method for the determination of serum lipase. Clin. Chem., 14, 1097. 1106.

Dole, V. P. (1956). A relation between non-esterified fatty acids in plasma and the metabolism of glucose. J. clin. Invest., 35, 150-154.

Hofmann, A. F. (1962). Thin-layer adsorption chromatography of free and conjugated bile acids on silicic acid. J. Lipid Res., 3, 127-128.

Israel, Y. J. E., Valenzuela, J. E., Salazar, I., and Ugarte, G. (1969). Alcohol and amino acid transport in the human small intestine. J. Nutr., 98, 222-224.

Krone, C. L., Theodor, E., Sleisenger, M. H., and Jeffries, G. H. (1968). Studies on the pathogenesis of malabsorption. Medicine (Baltimore), 47, 89-106.

Linscheer, W. G., Patterson, J. F., Moore, E. W., Clermont, R. J., Robins, S. J., and Chalmers, T. C. (1966). Medium and long chain fat absorption in patients with cirrhosis. $J$. clin Invest., 45, 1317-1325.

Linscheer, W. G., Roggin, G. M., and Patterson, J. F. (1970). On the etiology of fat absorption in alcoholic cirrhosis and improvement with medium chain triglycerides. (Abstr.) Gastroenterology, 58, 1012.

Mezey, E., Jow, E., Slavin, R. E., and Tobon, F. (1970). Pancreatic function and intestinal absorption in chronic alcoholism. Gastroenterolog y, 59, 657-664.

Roe, J. H., and Rice, E. W. (1948). A photometric method for the determination of free pentoses in animal tissues. J. biol. Chem., 173, 507-512.

Roggin, G. M., Iber, F. L., Kater, R. M. H., and Tobon, F. (1969). Malabsorption in the chronic alcoholic. Johns Hopk. med. J., 125, 321-330.

Shaper, A. G. (1964). Aetiology of chronic pancreatic fibrosis with calcification seen in Uganda. Brit. med. J., 1, 1607-1609.

Tandon, B. N., Banks, P. A., George, P. K., Sama, S. K., Ramachandran, K. and Gandhi, P. C. (1970). Recovery of exocrine pancreatic function in adult protein-calorie malnutrition. Gastroenterology, 58, 358-362.

Van Goidsenhoven, G. E., Henke, W. J., Vacca, J. B., and Knight, W. A., Jr. (1963). Pancreatic function in cirrhosis of the liver. Amer.J. dig. Dis., 8, 160.

van de Kamer, J. H., ten Bokkell, Huinink, H., and Weyers, H. A. (1949). Rapid method for the determination of fat in feces. J. biol. Chem., 177, 347-355.

Vlahcevic, Z. R., Buhac, I., Farrar, J. T., Cooper Bell, C., Jr., and Swell, L. Bile acid metabolism in patients w:th cirrhosis Gastroenterology, 60, 491-498. 